$12-1-2010$

\title{
Microdiscectomy for lumbosacral disc herniation and frequency of failed disc surgery
}

Muhammad Shahzad Shamim

Aga Khan University, shahzad.shamim@aku.edu

Maria Adnan Parekh

Aga Khan University

Muhammad Ehsan Bari

Aga Khan University, ehsan.bari@aku.edu

Ather Enam

Aga Khan University, ather.enam@aku.edu

Faraz Khursheed

Aga Khan University

Follow this and additional works at: https://ecommons.aku.edu/pakistan_fhs_mc_surg_neurosurg

Part of the Neurology Commons, Neurosurgery Commons, and the Surgery Commons

\section{Recommended Citation}

Shamim, M., Parekh, M., Bari, M., Enam, A., Khursheed, F. (2010). Microdiscectomy for lumbosacral disc herniation and frequency of failed disc surgery. World Neurosurgery, 74(6), 611-616.

Available at: https://ecommons.aku.edu/pakistan_fhs_mc_surg_neurosurg/27 


\title{
Microdiscectomy for Lumbosacral Disc Herniation and Frequency of Failed Disc Surgery
}

\author{
Muhammad Shahzad Shamim ${ }^{1}$, Maria Adnan Parekh², Muhammad Ehsan Bari ${ }^{1}$, Syed Ather Enam ${ }^{1,2}$, \\ Faraz Khursheed ${ }^{1}$
}

\author{
Key words \\ - Disc herniation \\ - Failed disc surgery \\ - Microdiscectomy
}

\begin{abstract}
Abbreviations and Acronyms
AKUH: Aga Khan University Hospital

BMI: Body mass index

CSF: Cerebrospinal fluid

FDS: Failed disc surgery
\end{abstract}

(* From the Departments of ${ }^{\mathbf{1}}$ Neurosurgery and ${ }^{2}$ Biological and Basic Sciences, Aga Khan University Hospital, Karachi, Pakistan

To whom correspondence should be addressed:

Muhammad Ehsan Bari, M.B.B.S.

[E-mail: ehsan.bari@aku.edu]

Citation: World Neurosurg. (2010) 74, 6:611-616.

DOI: 10.1016/j.wneu.2010.06.016

Journal homepage: www.WORLDNEUROSURGERY.org

Available online: www.sciencedirect.com

1878-8750/\$ - see front matter (C) 2010 Elsevier Inc. All rights reserved.

\section{INTRODUCTION}

Intervertebral disc herniation, or prolapsed intervertebral disc as a cause of sciatica, has a prevalence of $3 \%-4 \%$ and a lifetime incidence reaching $40 \%$, which makes it a major worldwide health problem (I5). Despite exponential progress in the understanding of the pathophysiological basis and in radiological imaging and microsurgical techniques, clinical audits consistently show failure to achieve the desired outcome in $3 \%-12 \%$ of patients depending on the outcome measure used $(7$, I2, I3, I5, 22, 29). Yorimitsu etal. (29) report a higher rate of failure than prior studies, with residual back pain in about $74 \%$ of patients and a reoperation rate of $\mathrm{I} 2 \%$. Several predictors for an unfavorable outcome of lumbar disc surgery in various populations have been identified (I, 3, 5, 6, 9, I6, 20, 2I, 23-26), including sociodemographic, clinical, work-related, and psychological variables. The aim of this retrospective study was to review the demographics of the patient population presenting for surgical treatment of lumbosacral disc herniations and to review the results of lumbosacral microdiscectomy at a single university hospital in Pakistan.

BACKGROUND: Microdiscectomy for lumbosacral disc herniations is one of the most commonly performed neurosurgical procedures. The patient demographics, symptomatology, and recovery are highly variable, and surgical outcomes depend on several factors, including patient demographics. Failed disc surgery refers to failure of improvement in patient's symptoms following microdiscectomy, and has been observed to occur in up to $12 \%$ of patients. To date, no study form Pakistan has looked into patient demographics and failed disc surgery rates within the local context.

OBJECTIVE: The aim of this study was to review the demographics of the patient population presenting for surgical treatment of lumbosacral disc herniations and to review our results of lumbosacral microdiscectomy at a university hospital in Pakistan.

METHODS: This is a retrospective analysis of all adult patients admitted from January 2003 to January 2008 for symptomatic lumbosacral disc herniation requiring microdiscectomy, at the Aga Khan University Hospital, Karachi. Data were collected through our medical records, on a standardized form. Basic information about the patient population, disease process, modes of nonsurgical treatment, and details on surgery and postoperative course were recorded and analyzed using SPSS.

RESULTS: Five hundred one patients were studied, based on inclusion criteria. The mean age was 41.2 years; 347 (69\%) patients were male and 154 (31\%) female. Mean body mass index of the population was 26 and was higher in females. All patients primarily presented with radiculopathy, and the mean duration of these symptoms was 438 days. Mean duration of nonoperative management was 53 weeks. Fifty-one patients (10.2\%) had previously undergone spine surgery. A total of 442 $(88 \%)$ patients were operated at single disc level, and the rest at two levels. Sixty-six $(13 \%)$ patients were operated for upper lumbar disc herniations. Mean operative time was 94 minutes, and the most common complication was dural tear. Mean length of hospital stay was 5 days (2-12 days). Mean follow-up was 48.3 weeks (4 weeks to 14 years). Complete resolution of symptoms was seen in $360(71.9 \%)$ patients and failed disc surgery was diagnosed in 42 (8.4\%) patients. Twenty-six patients $(5.2 \%)$ were reoperated upon, with gradual improvement. The authors report an overall failed back surgery rate of $8.38 \%$.

CONCLUSIONS: Overall our results were comparable to published international literature. However, the authors observed significant differences in demographics, especially in terms of age, gender distribution, and mean BMI of patient population as well as frequency of involvement of upper lumbar discs.

\section{MATERIALS AND METHODS}

This study was conducted at the Aga Khan University Hospital (AKUH), Karachi, Pakistan. The AKUH is one of the leading ter- tiary care facilities in the private sector, situated in a provincial capital and the most populous city of Pakistan. It caters to patients from all income groups, attracting people from all across the country to seek 
medical advice. The study was carried out using medical records of patients who underwent microdiscectomy and fit the inclusion criteria, from January 2003 to January 2008. Files were retrieved using codes from the International Classification of Diseases, version 9.o, Clinical Modifications. All patients, aged I8 years or older, admitted with symptomatic, medically refractory lumbosacral intervertebral disc herniation who underwent single- or multiple-level posterior microdiscectomy were included.

All surgeries were performed with the patient in general anesthesia, in prone position, placed on chest and pelvic cushions, with hips and knees flexed to improve interlaminar space. Intraoperative fluoroscopy was used to localize the level prior to incision and once again after exposure of lamina. Two- to 3 -cm skin incisions were used for single-level exposure and longer in case of multilevel exposure or obese patients. After incising the fascia, standard subperiosteal dissections were used to expose the lamina all the way to the start of facet joins laterally, to the upper surface of the lower lamina inferiorly and until the pars superiorly. Level was reconfirmed on fluoroscopy, and drilling of lamina was carried out with high-speed burr under microscope. Lamina was drilled until the origin of ligamentum flavum, from where it was peeled down to its attachment at the upper surface of the lower lamina. The ligamentum flavum was also removed from lateral recesses prior to nerve root retraction. Once the thecal sac and nerve root were clearly visualized, they were retracted at the level of the disc, and using a small cruciate incision over the annulus, free disc fragments were removed using pituitary rongeurs. A steroid-soaked gel foam was placed on the exposed nerve root and standard closure was carried out.

Patients with concomitant spinal or foraminal stenosis, patients who underwent decompressive procedures other than discectomy, and patients who underwent fusion were excluded from this study. Failed disc surgery (FDS) was defined as a condition where there was either no improvement in preoperative symptoms, or worsening of symptoms following surgery. Patients were identified as overweight or obese if their body mass index (BMI) was 23 $\mathrm{kg} / \mathrm{m}^{2}$ or greater. This definition, based on the revised criteria for Asian populations (28), was lower than the conventional cut- off value of $25 \mathrm{~kg} / \mathrm{m}^{2}$ for populations of European origin and reflects the higher ratio of body fat to muscle mass in the former. Obesity was defined as a BMI of $27 \mathrm{~kg} / \mathrm{m}^{2}$ or greater.

A standardized two-page form was used to collect data on patient demographics, presenting features, physical examination, neuroradiologic information, details of presurgical conservative management, surgical procedure, postoperative course and follow-ups.

All statistical analyses were performed using SPSS, version I3.0, for Windows. All data acquired in the precoded form were entered and checked twice on two separate occasions by two different investigators. Continuous variables were expressed as mean \pm standard deviation. Categorical variables were compared using $\chi^{2}$ and Fisher's exact tests, as applicable. A $P$ value $<0.05$ was considered statistically significant for all analyses.

\section{RESULTS}

The study criteria were met by 5 or patients with a mean age of 4I.2 years, of which 347 (69\%) were male and ${ }_{54}(3 \mathrm{I} \%)$ female. The mean BMI of the population was $26 \mathrm{~kg} / \mathrm{m}^{2}$ and was noted to be significantly higher in females $(27.3 \pm 6.5$ vs. $25.6 \pm 4.5, \mathrm{P}<$ 0.05 ). Ninety-five patients (I9\%) were previously diagnosed with hypertension; smoking was a feature in III $(22 \%)$, and obesity was observed in 99 (20\%) of patients. Overall, $96 \%$ of our patients were preoperative functional class I, and the rest class II. Details of clinical characteristics are outlined in Table $\mathbf{1 .}$

All patients primarily presented with lumbosacral radiculopathy; in addition, there were symptoms of numbness in $62 \%$ and motor weakness in $54 \%$. The mean duration of these symptoms was 438 days, with $80 \%$ of patients being affected for 3 to I2 months. The onset of pain was acute in $308(6 \mathrm{r} \%)$ patients and insidious in 193 (39\%). Fifty-one patients (I0.2\%) had previously undergone spine surgery, and II4 (22.8\%) had a history significant of trauma to the back. The mean duration of symptoms and inconsistent nonoperative management was 53 weeks prior to presentation at the AKUH, and 4 weeks as outpatient by us. Our policy is to try optimal nonoperative management for a minimum of 6 weeks prior to operating on a patient with symptomatic lumbosacral disc herniations, unless there is progressive neurologic deficit, cauda equina syndrome, or intolerable pain refractory to the best medical measures. Surgery is also considered earlier if the patient wishes not to try 6 weeks of medical and physical therapy.

Nonoperative measures include medications (including nonsteroidal antiinflammatory drugs and opioid derivatives), short bed rest, and physiotherapy. The various other forms of nonoperative management tried by these patients either prescribed by us or prescribed prior to presentation at our institute included oral analgesics $(85.4 \%)$, gabapentin analogues $(34.9 \%)$, mild muscle relaxants $(7 \%)$, transcutaneous electrical nerve stimulation ( $5 \%$ ), epidural steroid injections (4.2\%), traditional medicine $(3.8 \%)$, and even short-term trial with oral steroids (1.8\%). There was no symptomatic improvement in 248 patients $(49.3 \%)$, and 6I (I2.I\%) actually reported feeling worse (Figure 1). The remaining I98 patients (38.5\%) reported only limited improvement in symptoms after a full trial of nonoperative measures and chose to undergo surgery.

All patients presenting to the AKUH underwent preoperative magnetic resonance imaging of the lumbosacral spine, as the imaging modality of choice (Figures 2 and 3). Involvement of single lumbar disc level was seen in 442 patients ( $88 \%$ ) and multiple levels in 59 (12\%). Significant disc herniation with nerve root compression was identified in all 50 I patients, with $\mathrm{L}_{4} / \mathrm{L}_{5}$ being the most commonly affected level $(60 \%)$ followed closely by $\mathrm{L}_{5} / \mathrm{SI}_{\mathrm{I}}(44 \%)$. Sixty-six ( $13 \%)$ patients had disc involvement at levels other than $\mathrm{L}_{4} / 5$ or $\mathrm{L}_{5} / \mathrm{SI}_{\mathrm{I}}$ levels, that is, upper lumbar disc herniations.

The average number of surgeries performed yearly during this 5 -year period at the AKUH was 10o. Eighty-four percent of patients were operated upon by neurospinal surgeons and the remaining by orthopedic spine surgeons, with a mean operative time of $99.3( \pm 45)$ minutes. A total of 442 ( $88 \%)$ patients were operated at a single disc level, the rest at two levels, and none at more than two levels. The most common complications were intraoperative dural tear $(n=43$, $8.6 \%$ ), and postoperative superficial wound infection ( $n=10,2 \%$ ). Other complications are mentioned in Table 2. None of the pa- 


\section{Table 1. Clinical Characteristics of the Patient Population}

\begin{tabular}{|c|c|}
\hline Basic demographics & \\
\hline Number of patients & 501 \\
\hline Male & 347 \\
\hline Female & 154 \\
\hline Age (in years)* & $41.2 \pm 12$ \\
\hline Body mass index (BMI)* & $26.1 \pm 5.2$ \\
\hline Male & $25.6 \pm 4.5$ \\
\hline Female & $27.3 \pm 6.5$ \\
\hline
\end{tabular}

Marital status

Married

Unmarried

Widowed

Divorced

Comorbid conditions

Cigarette smoking

Obesity

Hypertension

Ischemic heart disease

Diabetes type II

Depression/anxiety

Peptic ulcer disease

Functional class by activity

I (no limitation)

II (mild limitation)

Presenting features

Onset

$$
\text { Acute }
$$

Insidious

Lower limb numbness

Lower limb paresis

Neurogenic claudication

Duration of symptoms (days)*

Significant past history

Prior spine surgery

Discectomy

Laminectomy

Back trauma

${ }^{*}$ Mean \pm SD.

tients in the two groups required further reoperation for their complications, and settled on conservative management, in the

$\%$

69.3

30.7

54

\begin{tabular}{|r|r|}
\hline 423 & 84.4 \\
\hline 34 & 6.8 \\
\hline 41 & 8.2 \\
\hline 3 & 0.6 \\
\hline
\end{tabular}

\begin{tabular}{|r|r|}
\hline 111 & 22.2 \\
\hline 99 & 19.8 \\
\hline 94 & 18.8 \\
\hline 31 & 6.2 \\
\hline 42 & 8.4 \\
\hline 8 & 1.6 \\
\hline 32 & 6.4 \\
\hline
\end{tabular}

\begin{tabular}{|r|r|}
\hline 480 & 96.0 \\
\hline 21 & 4.0 \\
\hline
\end{tabular}

\begin{tabular}{|c|c|}
\hline \multicolumn{2}{|l|}{308} \\
\hline 193 & \\
\hline 312 & 62.3 \\
\hline 270 & 53.9 \\
\hline 87 & 17.4 \\
\hline
\end{tabular}

\begin{tabular}{|r|r|}
\hline 51 & 10.2 \\
\hline 35 & \\
\hline 16 & \\
\hline 114 & 22.8 \\
\hline
\end{tabular}

form of bed rest and/or lumbar drain placement for cerebrospinal fluid (CSF) leaks and antibiotics for wound infections. The mean length of hospital stay was 5 days (2-I2 days).

Patients were followed in the outpatient clinic for a mean period of 48.3 weeks ( 4 weeks to I4 years). Complete resolution of symptoms was seen in 360 (71.9\%) patients. Forty-two $(8.4 \%)$ patients either did not show any improvement or expressed worsening of their symptoms after surgery. Of these, 35 patients ( $7 \%$ ) were readmitted within 30 days, and 26 patients (5.2\%) had to be reoperated upon, with gradual improvement of their symptoms. The rest were managed with conservative measures and also showed improvement with time.

\section{DISCUSSION}

To our knowledge, this is the largest consecutive series of patients reported from a single university hospital in Pakistan to date (2). Therefore, the results of this study will not only serve as important baseline information on patients undergoing microdiscectomy in Pakistan but can also be compared with local and international literature for patient demographics and surgical outcomes. The fact that the data are composed of consecutive patients also gives us valuable insight into the trends of surgical practice at our tertiary care center, which in the absence of local literature may be extrapolated to represent Pakistan, at least until further reports are published.

The mean age of our patients was 4I years, which is less than that recorded in published literature (4). We found a large discrepancy in gender distribution, with almost $70 \%$ of our patient population being male. Previous reports published on disc surgery have not had such gender disproportion $(5,6,8$, I0, 13, 20). Interestingly, our local data are rich with male predisposition for diseases not previously known to have any specific gender preferences (I8, I9). Also of interest is that all I54 female patients operated at our center were nonprofessional housewives. Almost 20\% of the patients who underwent surgery were overweight or obese (BMI $\geq 23 \mathrm{~kg} / \mathrm{m}^{2}$ ), based on the revised criteria for Asian populations (28). The mean BMI of our patients was $26 . \mathrm{rg} / \mathrm{m}^{2}$ and was significantly higher in the female patient group as compared to the males ( 27.3 vs. $\left.25.6 \mathrm{~kg} / \mathrm{m}^{2}, \mathrm{P}<0.05\right)$. These findings are peculiar as the study comes from a low-income country, with a 


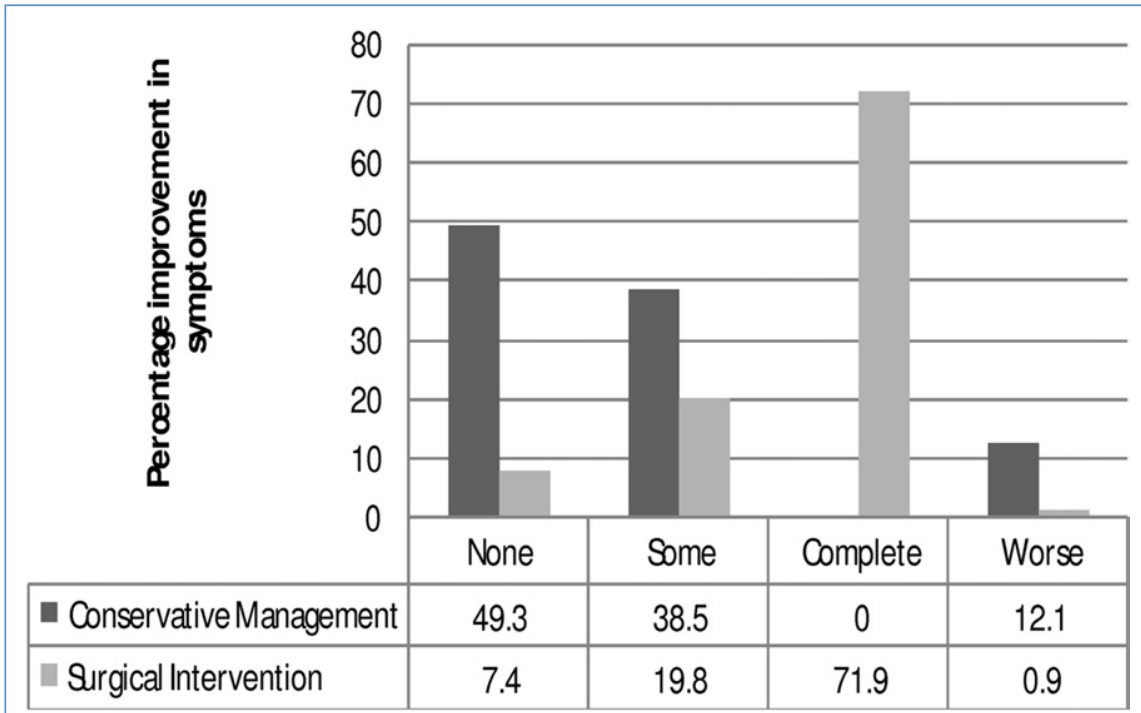

Figure 1. Breakup of patients with respect to their response to conservative management and following surgical intervention.

gross national income per capita of $\$ 800$ in 2006 compared with an average income per capita of $\$ 38$, I90 in developed countries (27). One would assume that in a low-economic-status country that average BMI would be less than a high economic country. As also reported in the literature, the most common levels of involvement in our study were also $\mathrm{L}_{4} / 5$, followed by $\mathrm{L}_{5} / \mathrm{SI}_{\text {I }}$ (4). It may be pointed out here that our frequency of operating on upper lumbar disc herniations ( $13 \%$ ) was significantly greater than that reported in large series in international literature (I4).

Our mean operative time was almost an hour and a half. This is a little higher than would be ideally expected. At this point, it should be recalled that $\mathrm{I} 2 \%$ of our patients were operated at more than one level and Io\% had undergone a prior spine surgery;

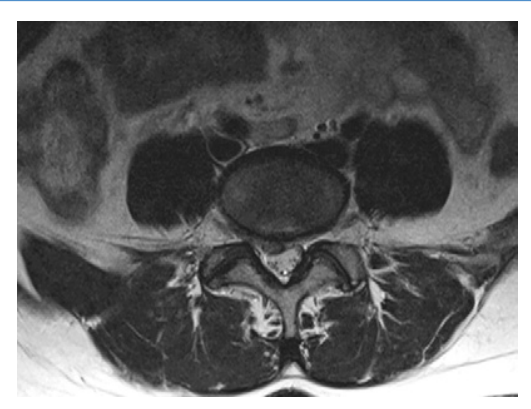

Figure 2. Pre-operative axial image of L4-L5 disc fragment both these factors significantly increase the operative time. It may also be pertinent to note that our center is involved in postgraduate training of both neurosurgery and orthopedics surgery students, and the duration of surgery is therefore expected to be longer. The mean duration of hospital stay of our patients was 5 days, which is not truly representative. Since the introduction of inpatient clinical pathways, as a routine our patients who undergo microdiscectomy are

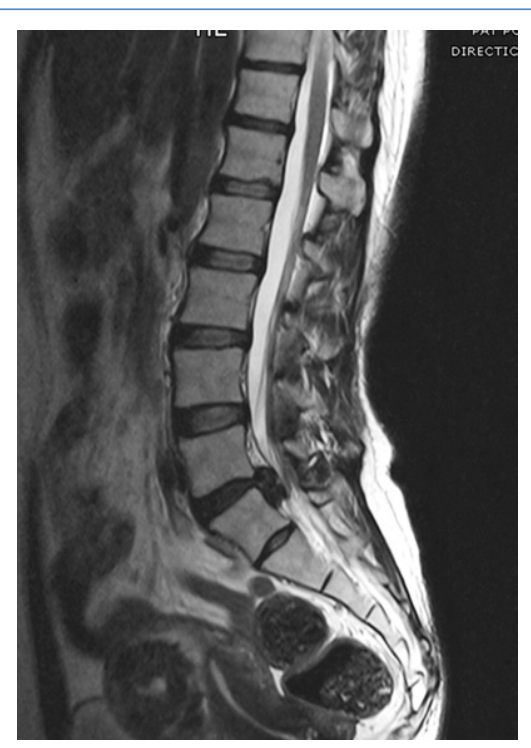

Figure 3. Pre-operative sagittal image of L4-L5 disc fragment discharged within $24-36$ hours of surgery. In the present context, the mean hospital stay also incorporates patients who were initially admitted for inpatient pain control as well as patients who had an extended stay because of complications such as CSF leak. Moreover, our patients prefer to stay in hospital for longer than clinically indicated, as a lot of them do not have local accommodation and one is not provided by the hospital.

Despite microdiscectomy being the most common neurosurgical procedure performed worldwide, studies have reported that failure to achieve the desired outcome occurs in $10 \%-15 \%$ of patients $\left(7, \mathrm{I}_{2}, \mathrm{I}_{3}, \mathrm{I}_{5}\right.$, 22, 29). We also report an overall FDS rate of $8.4 \%$, varying minimally over the 5 -year study period, with a reoperation rate of $5.2 \%$. All patients who were reoperated upon, required surgery within the first 6 weeks of the index procedure, with no other patients requiring a second surgery at a mean follow-up of 48.3 weeks. The indication of reoperation in these patients was either recurrent or residual disc herniation. Microdiscectomy was thus undertaken, with no patient requiring a more extensive decompression or fusion. No intraoperative or postoperative complications were observed as a consequence of the second surgery. All patients made fair to excellent recovery after their second operation, which was usually followed by an extended course of in-patient and later out-patient physical therapy. Comparison of our FDS rate with some published series is shown in Table 3.

Microdiscectomy is generally considered a safe procedure with an extremely low incidence of postoperative complications $(4,6$, 7 , II, I4, I7), with less than I0\% patients on average requiring revision (II, 23, 29). The most common complications that we observed in our series were intraoperative dural tear $(\mathfrak{n}=43,8.6 \%)$ and superficial wound infection ( $n=10,2.0 \%)$. Intraoperative dural tear was managed with intraoperative watertight closure of dura, occasionally augmented with application of fibrin glue, and postoperative immobilization for 48-72 hours. We encountered only one case of postoperative CSF leak, which required temporary lumbar drainage for another 48 hours. All superficial wound infections were successfully treated with a I-week course of oral antibiotics as outpatient. Overall our complication rates were 


\begin{tabular}{|c|c|c|}
\hline & $n$ & $\%$ \\
\hline \multicolumn{3}{|l|}{ Surgery } \\
\hline Single level & 445 & 88.1 \\
\hline Multiple level & 60 & 11.9 \\
\hline Operative time (in minutes) ${ }^{*}$ & $99.3 \pm 45$ & \\
\hline \multicolumn{3}{|l|}{ Operating surgeon } \\
\hline Neurospinal surgeon & & 84 \\
\hline Orthopedic spine surgeon & & 16 \\
\hline \multicolumn{3}{|l|}{ Complications } \\
\hline Incidental durotomy & 43 & 8.6 \\
\hline Negative exploration & 7 & 1.4 \\
\hline Bleeding from epidural plexus & 2 & 0.4 \\
\hline CSF leak & 1 & 0.2 \\
\hline Wound infection & 10 & 2.0 \\
\hline Hematoma & 1 & 0.2 \\
\hline Others & 2 & 1.4 \\
\hline \multicolumn{3}{|l|}{ Failed disc surgery } \\
\hline No symptomatic improvement & 33 & 6.6 \\
\hline Worsening of symptoms & 3 & 0.6 \\
\hline Readmission within 30 days & 35 & 7.0 \\
\hline Reoperation within 6 weeks & 26 & 5.2 \\
\hline $\begin{array}{l}\text { CSF, cerebrospinal fluid. } \\
{ }^{*} \text { Time from incision to dressing. }\end{array}$ & & \\
\hline
\end{tabular}

comparable with those in the published literature.

We would like to highlight a few limitations of our review. One, data were retrospectively collected and although the introduction of thorough clinical pathways has resulted in detailed patient information, the authors were still not able to evaluate certain variables that would have been of interest to readers, such as type of disc herniations, and pre- and postoperative Oswestry Disability Indices. Our study population consisted of only those patients who failed nonoperative trials, typically reported to be effective in more than $80 \%$ patients with sciatica (23). It cannot be extrapolated to represent the general population of patients with sciatica and, therefore, our statistics must be interpreted with caution.

The overall FDS rate seen in our patient population is comparable to international studies published previously. However, prior studies have reported differences in the basic demography and epidemiologic profile of Pakistan and countries of Europe and America. The authors observed that Pakistani patients undergoing lumbar microdiscectomy are younger, more likely to be males, and with a higher BMI $(\mathrm{P}<0.05)$. Moreover, the mode of health care financing is in stark contrast to developed countries; that is, in Pakistan $82 \%$ of the total

Table 3. Reported Rates of Failed Disc Surgery

\begin{tabular}{|c|c|c|c|c|c|}
\hline Study & Year & Population & Sample size & Outcome measure & Reported FDS (\%) \\
\hline \multirow[t]{2}{*}{ Shamim et al. } & \multirow[t]{2}{*}{2010} & \multirow[t]{2}{*}{ Pakistan } & \multirow[t]{2}{*}{501} & Same/worse symptoms & 8.4 \\
\hline & & & & Reoperation rate & 5.2 \\
\hline Cummins et al. (4) & 2006 & 11 U.S. states & $\begin{array}{l}\text { 501, of which } 232 \\
\text { underwent discectomy }\end{array}$ & Reoperation within 2 years & 5.0 \\
\hline Dewing et al. (6) & 2008 & San Diego, USA & 183 & Recurrent disc herniation & 3.0 \\
\hline Morgan-Hough et al. (15) & 2003 & England & 531 & Reoperation rate & 7.9 \\
\hline Loupasis et al. (13) & 1999 & Greece & 109 & Reoperation rate & 7.3 \\
\hline Solberg et al. (20) & 2005 & Norway & 180 & ODI score at 12 months $>39$ & 6.7 \\
\hline \multirow[t]{2}{*}{ Gaetani et al. (8) } & \multirow[t]{2}{*}{2004} & \multirow[t]{2}{*}{ Italy } & \multirow[t]{2}{*}{403} & Surgical recurrence & 8.9 \\
\hline & & & & Radiological recurrence & 15.1 \\
\hline Keskimaki et al. (10) & 2000 & Finland & 25,359 & Reoperation rate & 12.3 \\
\hline den Boer et al. (5) & 2006 & The Netherlands & 277 & $\begin{array}{l}\text { Intense pain (VAS score } \geq 30 \text { ) } \\
\text { at } 6 \text { months postoperation }\end{array}$ & 25 \\
\hline Yorimitsu et al. (29) & 2001 & Japan & - & Reoperation rate & 12.7 \\
\hline
\end{tabular}


spending on health care is privately financed, compared to organization of economic cooperation for developed countries with an average of $26 \%$. More prominently, almost all private spending on health care in Pakistan is out-of-pocket ( $98 \%$ ), whereas in high-income countries, the average out-ofpocket expenditure on health is $36 \%$ of the total health expenditure. In lieu of these considerations, our results may not be truly reflective of the actual scenario.

\section{CONCLUSION}

As compared to published international literature, the authors observed significant differences in demographics, especially in terms of age, BMI, gender distribution, and involvement of upper lumbar discs. Overall our results are comparable to published international literature.

\section{REFERENCES}

I. Abramovitz JN, Neff SR: Lumbar disc surgery: results of the Prospective Lumbar Discectomy Study of the Joint Section on Disorders of the Spine and Peripheral Nerves of the American Association of Neurological Surgeons and the Congress of Neurological Surgeons. Neurosurgery 29:30I-7, I99I.

2. Akbar A, Mahar A: Lumbar disc prolapse: management and outcome analysis of 96 surgically treated patients. J Pak Med Assoc 52:62-5, 2002.

3. Asch HL, Lewis PJ, Moreland DB, Egnatchik JG, Yu YJ, Clabeaux DE, Hyland AH: Prospective multiple outcomes study of outpatient lumbar microdiscectomy: should 75 to $80 \%$ success rates be the norm? J Neurosurg 96(I Suppl):34-44, 2002.

4. Cummins J, Lurie JD, Tosteson TD, Hanscom B, Abdu WA, Birkmeyer NJ, Herkowitz H, Weinstein J: Descriptive epidemiology and prior healthcare utilization of patients in the Spine Patient Outcomes Research Trial's (SPORT) three observational cohorts: disc herniation, spinal stenosis, and degenerative spondylolisthesis. Spine I:3r:806-I4, 2006.

5. den Boer JJ, Oostendorp RA, Beems T, Munneke M, Evers AW: Continued disability and pain after lumbar disc surgery: the role of cognitive-behavioral factors. Pain $123: 45-52,2006$.

6. Dewing CB, Provencher MT, Riffenburgh RH, Kerr $\mathrm{S}$, Manos RE: The outcomes of lumbar microdiscec- tomy in a young, active population: correlation by herniation type and level. Spine 33:33-8, 2008.

7. Findlay GF, Hall BI, Musa BS, Oliveira MD, Fear SC: A ro-year follow-up of the outcome of lumbar microdiscectomy. Spine 23:II68-7I, I998.

8. Gaetani P, Aimar E, Panella L, Debernardi A, Tancioni F, Rodriguez y Baena R: Surgery for herniated lumbar disc disease: factors influencing outcome measures. An analysis of 403 cases. Funct Neurol 19:43-9, 2004.

9. Greenough CG: Results of treatment of lumbar spine disorders. Effects of assessment techniques and confounding factors. Acta Orthop Scand Suppl 251:126-9, I993.

Io. Keskimäki I, Seitsalo S, Osterman H, Rissanen P: Reoperations after lumbar disc surgery: a population-based study of regional and interspecialty variations. Spine 25:1500-8, 2000.

II. Koebbe CJ, Maroon JC, Abla A, El-Kadi H, Bost J: Lumbar microdiscectomy: a historical perspective and current technical considerations. Neurosurg Focus $\mathrm{I}_{3}: \mathrm{E}_{3}, 2002$.

I2. Korres DS, Loupasis G, Stamos K: Results of lumbar discectomy: a study using I5 different evaluation methods. Eur Spine J I:20-4, I992.

13. Loupasis GA, Stamos K, Katonis PG, Sapkas G, Korres DS, Hartofilakidis G: Seven- to 20-year outcome of lumbar discectomy. Spine 24:2313-7, 1999.

I4. Lurie JD, Faucett SC, Hanscom B, Tosteson TD, Ball PA, Abdu WA, Frymoyer JW, Weinstein JN: Lumbar discectomy outcomes vary by herniation level in the Spine Patient Outcomes Research Trial. J Bone Joint Surg Am 90:I8II-9, 2008.

I5. Morgan-Hough CV, Jones PW, Eisenstein SM: Primary and revision lumbar discectomy. A I6-year review from one centre. J Bone Joint Surg Br 85:87I-4, 2003.

I6. Nygaard OP, Kloster R, Solberg T: Duration of leg pain as a predictor of outcome after surgery for lumbar disc herniation: a prospective cohort study with I-year follow up. J Neurosurg 92(2 Suppl):I3I-4, 2000.

17. Peul WC, van Houwelingen HC, van den Hout WB, Brand R, EekhofJA, Tans JT, Thomeer RT, Koes BW; Leiden-The Hague Spine Intervention Prognostic Study Group: Surgery versus prolonged conservative treatment for sciatica. N Engl J Med 356:2245-56, 2007.

I8. Shamim MS, Bari ME, Khursheed SF, Jooma R, Enam SA: Pituitary adenomas: demographic differences and surgical outcomes in a South Asian country. Can J Neurol Sci 35:198-203, 2008.
I9. Shamim MS, Hameed K: Surgically treated rectal prolapse: experience at a teaching hospital. J Pak Med Assoc 55:247-50, 2005.

20. Solberg TK, Nygaard OP, Sjaavik K, Hofoss D, Ingebrigtsen T: The risk of "getting worse" after lumbar microdiscectomy. Eur Spine J I4:49-54, 2005.

2I. Sorensen LV, Mors O: A two-year prospective follow-up study of the outcome after surgery in patients with slipped lumbar disk operated upon for the first time. Acta Neurochir (Wien) 96:94-9, I989.

22. Spangfort EV: The lumbar disc herniation. A computer-aided analysis of 2,504 operations. Acta Orthop Scand Suppl I42:I-95, I972.

23. Weber H: Lumbar disc herniation: a controlled, prospective study with ten years of observations. Spine 8:I3I-40, I983.

24. Woertgen C, Holzschuh M, Rothoerl RD, Brawanski A: Does the choice of outcome scale influence prognostic factors for lumbar disc surgery? A prospective, consecutive study of I2I patients. Eur Spine J 6:173-80, I997.

25. Woertgen C, Rothoerl RD, Breme K, Altmeppen J, Holzschuh M, Brawanski A: Variability of outcome after lumbar disc surgery. Spine 24:807-II, I999.

26. Woertgen C, Rothoerl RD, Holzschuh M, Breme K, Brawanski A: Are prognostic factors still what they are expected to be after long-term followup? J Spinal Disord II:395-9, I998.

27. World Bank HNP Stats, On line data query system, Population and Nutrition Program, http://web.world bank.org/WBSITE/EXTERNAL/TOPICS/EXTHEALTH NUTRITIONANDPOPULATION/EXTDATASTATISTICS HNP/EXTHNPSTATS/o,,menuPK:3237172_pagePK: 64I68427_piPK:64I68435_theSitePK:3237II8,oo.html.

28. World Health Organization, Western Pacific Region: The International Association for the Study of Obesity and the International Obesity Task Force. The Asia-Pacific perspective: redefining obesity and its treatment. Sydney, Australia: Health Communications Australia; 2000.

29. Yorimitsu E, Chiba K, Toyama Y, Hirabayashi K: Long-term outcomes of standard discectomy for lumbar disc herniation: a follow-up study of more than ro years. Spine 26:652-7, 2001 .

Conflict of interest statement: The authors declare that the article content was composed in the absence of any commercial or financial relationships that could be construed as a potential conflict of interest.

received 02 February 2010; accepted 02 June 2010 Citation: World Neurosurg. (2010) 74, 6:611-616. DOl: 10.1016/j.wneu.2010.06.016

\section{Journal homepage: www.WORLDNEUROSURGERY.org}

\section{Available online: www.sciencedirect.com}

1878-8750/\$ - see front matter (C) 2010 Elsevier Inc. All rights reserved.

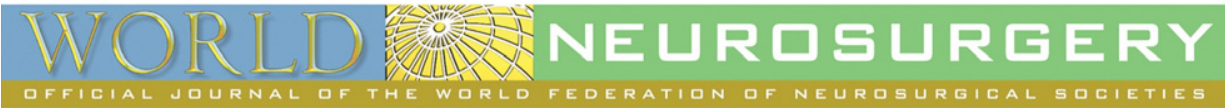

